\title{
ESPECTROMETRIA DE RAIOS GAMA DE GRANITOS PEGMATÍTICOS DA PROVÍNCIA PEGMATÍTICA DA BORBOREMA (PPB), NORDESTE DO BRASIL
}

\author{
Sebastião Milton Pinheiro da Silva ${ }^{1}$, Alvaro Penteado Crósta ${ }^{2}$, Francisco José Fonseca Ferreira ${ }^{3}$, \\ Hartmut Beurlen ${ }^{4}$, Adalene Moreira Silva ${ }^{5}$ e Luiz Fernando dos Santos ${ }^{6}$ \\ Recebido em 29 julho, 2009 / Aceito em 23 agosto, 2010 \\ Received on July 29, 2009 / Accepted on August 23, 2010
}

\begin{abstract}
The objective of this study is the characterization of pegmatitic granites located in the southern region of the Borborema Pegmatitic Province (BPP) with aerial and ground gamma ray data. Ground gamma ray data, radiometric and ICP-MS laboratory analysis showed that these granites have uranium concentrations varying between $0.4 \mathrm{ppm}$ and $7.8 \mathrm{ppm}$, thorium concentrations varying between $0.1 \mathrm{ppm}$ and $21 \mathrm{ppm}$ and potassium concentrations varying between $2 \%$ and $5.2 \%$. Based on these radiometric characteristics and using individual, ratios and ternary images of radioelements of aerial gamma ray data it was possible to distinguish from others country rocks a group of granitic pegmatitic bodies and also to individualize quartzitic formations from the northern and southern portions of the area, based on their different thorium (Th) contents. Ground gamma ray data, acquired for one of these pegmatitic granites, called Galo Branco granite, reveals an irregular spatial distribution of radioelements, indicating mineralogical changes in contents and concentrations of accessory minerals during magmatic crystalization. Pegmatites intruding quartzites in the south portion of the granite were also distinguished using eU/eTh and eU/K ratios images. The results indicated the potential of these methods for the characterization and mapping of pegmatitic granites and associated pegmatites of the Borborema Pegmatitic Province (BPP).
\end{abstract}

Keywords: gamma ray spectrometry, remote sensing, granites, pegmatites, Borborema Pegmatitic Province.

RESUMO. 0 presente estudo tem como objetivo a caracterização de granitos pegmatíicos localizados na região sul da Província Pegmatíica da Borborema (PPB) usando dados de aerogamaespectrométricos e de gamaespectrometria terrestre. Medidas gamaespectrométricas terrestres, dosagens radiométricas e determinações químicas por ICP-MS indicaram concentrações de urânio variando entre 0,4 ppm e 7,8 ppm, concentrações de tório entre 0,1 ppm e 21 ppm e concentrações de potássio entre $2 \%$ e 5,2\%. Com base nessas características, e utilizando imagens dos canais individuais, das razões de canais e da composição ternária dos radioelementos foi possível diferenciar das rochas encaixantes regionais um conjunto de granitos pegmatíticos e também diferenciar quartzitos das regiões norte e sul da área investigada com base nas concentrações mais elevadas de tório (Th) nestes últimos. Dados de gamaespectrometria terrestre de detalhe coletados em um desses granitos pegmatíticos conhecido como granito Galo Branco, revelaram irregularidades na distribuição espacial de radioelementos, sugerindo mudanças de conteúdo e concentração de minerais acessórios durante a diferenciação e cristalização magmática da rocha. Pegmatitos encaixados em quartzitos ao sul do granito Galo Branco foram individualizados com base nas razões eU/eTh e eU/K. Os resultados revelam grande potencial dos métodos para a caracterização e mapeamento geológico de granitos e pegmatitos da PPB.

Palavras-chave: gamaespectrometria, sensoriamento remoto, granitos, pegmatitos, Província Pegmatítica da Borborema.

\footnotetext{
1 Laboratório de Geoprocessamento, Departamento de Geografia, Universidade Federal do Rio Grande do Norte (UFRN), Campus Universitário, Lagoa Nova, Caixa Postal 1528, 59072-960 Natal, RN, Brasil. Tel.: (84) 3215-3571, ramal 2502 - E-mail: smpsilva@cchla.ufrn.br; sebastiaomilton@gmail.com

2 Instituto de Geociências, Universidade Estadual de Campinas (Unicamp), Campus Universitário Zeferino Vaz, Rua João Pandiá Calógeras, 51, Barão Geraldo, 13083-870 Campinas, SP, Brasil. Tel.: (19) 3521-5120, Fax: (19) 3289-1562 - E-mail: alvaro@ige.unicamp.br

3 Laboratório de Pesquisas em Geofísica Aplicada - LPGA, Curso de Pós-Graduação em Geologia, Departamento de Geologia, Universidade Federal do Paraná (UFPR), Centro Politécnico, Jardim das Américas, Caixa Postal 19045, 81531-980 Curitiba, PR, Brasil. Tel./Fax: (41) 3361-3132 - E-mail: francisco.ferreira@ufpr.br

${ }^{4}$ Programa de Pós-Graduação em Geociências, Universidade Federal de Pernambuco (UFPE), Rua Acadêmico Hélio Ramos s/n, Cidade Universitária, 50740-530 Recife, PE, Brasil-E-mail: beurlen@terra.com.br

${ }^{5}$ Laboratório de Geofísica Aplicada, Instituto de Geociências da Universidade de Brasília (UnB), 70910-900 Brasília, DF, Brasil - E-mail: adalene@unb.br

${ }^{6}$ Rua Carlos Weber, 1319, apto. 43P, Vila Hamburguesa, São Paulo, SP, Brasil - E-mail: LFSantos.geo@gmail.com
} 


\section{INTRODUÇÃo}

A Faixa Seridó - FSe (Jardim de Sá, 1994) abriga uma grande variedade de rochas graníticas de idade Neoproterozóica classificadas a partir de suas relações litoestruturais com as fases de deformação regionais D1 a D4 em quatro grandes grupos principais denominados G1 a G4 (Jardim de Sá et al., 1981).

AFSe contém mais de 1.500 pegmatitos (Da Silva et al., 1995) produtores de metais raros (Be, Ta-Nb, Li e Sn), de minerais gemas, como a "turmalina Paraíba", e de minerais industriais, como feldspato cerâmico, caulim e quartzo. A área de ocorrência dos pegmatitos corresponde a cerca de $10.000 \mathrm{~km}^{2}$, constituindo 0 que Scorza (1944) denominou de Província Pegmatítica da Borborema (PPB).

Alguns autores atribuem ao plutonismo granítico e às zonas de cisalhamento regionais, o papel de agentes importantes na geração de fluídos para as mineralizações de Ta-Nb, Sn, Be e Li em pegmatitos da PPB (Legrand et al., 1993; Da Silva, 1993) e também de ouro em veios de quartzo (Luiz-Silva, 2000).

Os granitos pegmatíiticos se destacam no contexto do plutonismo granítico Neoproterozóico da FSe devido às suas características similares a granitos férteis, pelo que têm sido considerados como possíveis termos intermediários entre 0 granito parental e os pegmatitos mineralizados da PPB (Da Silva \& Staerk, 1989; Da Silva \& Guimarães, 1992; Da Silva, 1993).

A aerogamaespectrometria é rotineiramente utilizada em atividades de mapeamento geológico (Ferreira, 1997; Santos et al., 1999; Oliveira et al., 2001; Dantas et al., 2003), na exploração mineral de variados tipos de mineralização (Saunders et al., 1993; Pires, 1995; Shives et al., 2000; Pascholati et al., 2003) e na caracterização e classificação de rochas graníticas (Galbraith \& Saunders, 1983; Portnov, 1987; Maurice \& Charbonneau, 1987; Ferreira et al., 2009; Ulbricht et al., 2009).

Nas rochas graníticas, o potássio tende a ser enriquecido em relação ao tório nos estágios tardios de diferenciação e cristalização magmática, e também em zonas de alteração hidrotermal. Baixos valores da razão eTh/K são potenciais indicadores da ocorrência dessas zonas (Shives et al., 2000). A família dos granitos peraluminosos costuma apresentar altos valores da razão eU/eTh, uma vez que o urânio se concentra, juntamente com a sílica, durante 0 fracionamento e a cristalização magmática, contrariamente ao tório (Maurice \& Charbonneau, 1987).

A ocorrência de pequenos stocks e domos de granitos pegmatíticos encaixados em quartzitos, biotita xistos, metaconglomerados e gnaisses da porção sul da PPB motivou a realização deste estudo no sentido de avaliar a discriminação radiométrica dessas rochas, utilizando os dados aerogamaespectrométricos disponíveis para a região.
Apesar da baixa resolução espacial destes dados, em relação às dimensões normalmente reduzidas dos granitos, decidiu-se reprocessá-Ios com os seguintes objetivos: i) caracterizar o comportamento gamaespectrométrico regional e ii) investigar as relações espaciais e radiométricas entre granitos e pegmatitos.

\section{LOCALIZAÇÃO E ASPECTOS FISIOGRÁFICOS}

$A$ área analisada é limitada pelas seguintes coordenadas geodésicas: $06^{\circ} 45^{\prime}$ e $07^{\circ} 15^{\prime}$ de latitude sul e $36^{\circ} 20^{\prime}$ e $36^{\circ} 50^{\prime}$ de longitude oeste. Ela está situada entre os estados da Paraíba e do Rio Grande do Norte, na região Nordeste do Brasil (Fig. 1).

Trata-se de região de clima quente, semi-árido, com precipitação pluviométrica escassa e mal distribuída. 0 relevo é bastante acidentado, com cotas variando de 250 metros no pediplano regional a 850 metros de altitude nas Serras de Santana e do Bonfim ao Sul, e das Queimadas e dos Quintos ao Norte, das cidades de Junco do Seridó (PB) e Equador (RN), respectivamente. A vegetação é arbustiva, rarefeita, espinhosa, normalmente composta por folhas pequenas, típica das espécies de caatinga.

\section{ASPECTOS GEOLÓGICOS REGIONAIS}

Do ponto de vista geotectônico, a área de estudo está inserida na Província Borborema, no Domínio Rio Grande do Norte (DRGN), mais precisamente no extremo sudeste da Faixa Seridó (FSe), (Almeida et al., 1977, 1981; Jardim de Sá, 1994; Brito Neves et al., 2000) (Fig. 1).

A denominação de Província Borborema foi introduzida por Almeida et al. (1977) para descrever na região Nordeste do Brasil, o mosaico de faixas dobradas e maciços granítico-gnássicomigmatíticos com estruturação geral em forma de leque de direção geral N-NE, resultante da colagem de terrenos Neoproterozóicos durante evento orogênico Brasiliano/Pan-africano (Jardim de Sá, 1994; Santos et al., 1999; Brito Neves et al., 2000; Van Schmus et al., 2003; Oliveira, 2008).

Sua estruturação geral realçada por extensas zonas de cisaIhamento regionais, contribui para dividi-la, em função das características litoestruturais e geocronológicas, em vários domínios e subdomínios geológicos, destacando-se dentre eles a Faixa Seridó (Jardim de Sá, 1994; Santos et al., 1999; Brito Neves et al., 2000; Van Schmus et al., 2003; Oliveira, 2008).

Segundo Oliveira (2008), os limites internos mais importantes da província estão representados pelas zonas de cisalhamento (ZCs) Pernambuco-Congo, Patos e Jaguaribe-Tatajuba, as quais possibilitam dividir a província nos seguintes domínios geofísicogeotectônicos: Sul ou Externo, Transversal, Rio Grande do Norte, Ceará e Médio Coreaú. 


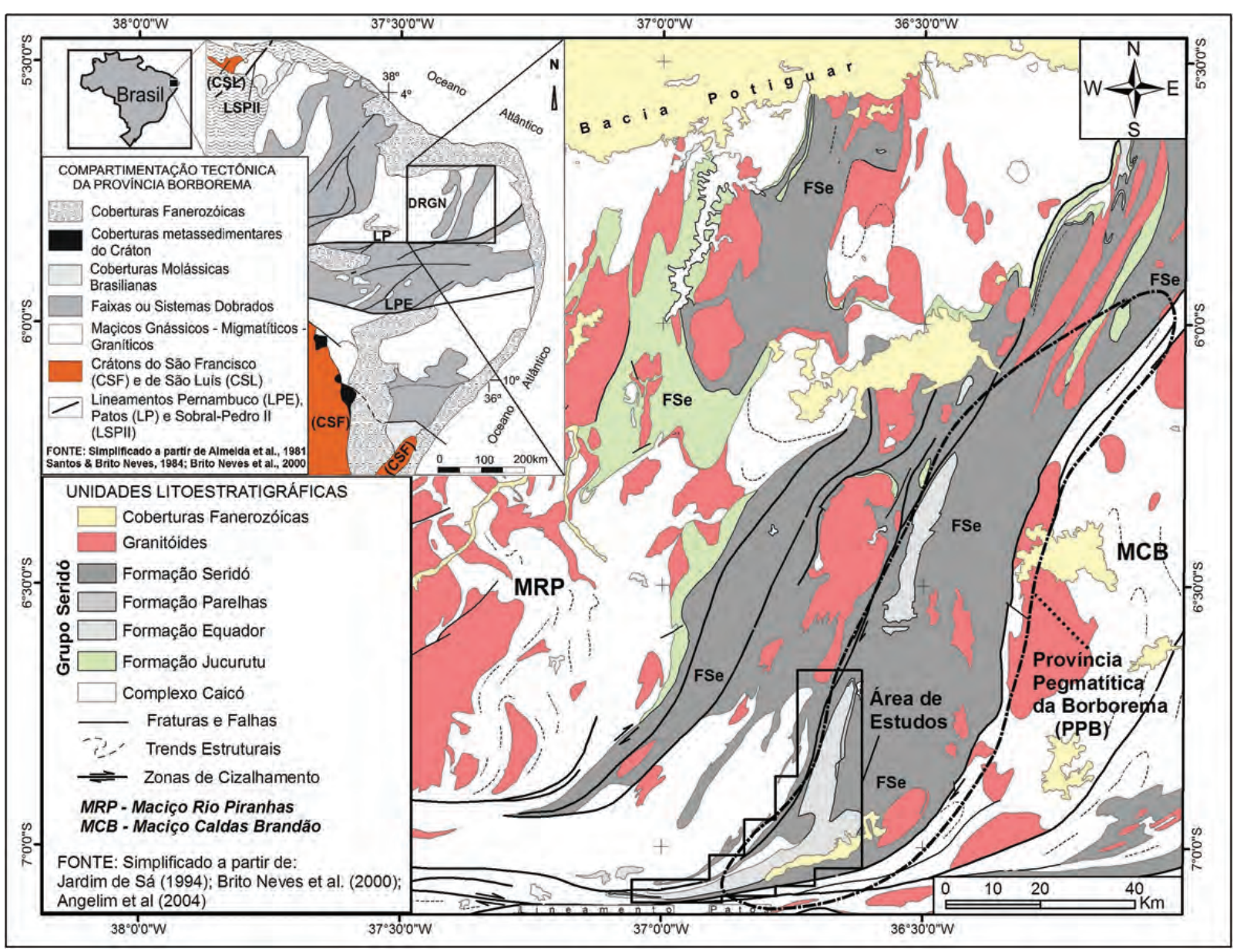

Figura 1 - Esboço geológico-geotectônico da Província Borborema e da Faixa Seridó, indicando a localização da área de estudo.

A FSe constitui importante segmento crustal da Província Borborema. Compreende uma sequência metavulcanossedimentar de idade Neoproterozóica (Grupo Seridó), repousando discordantemente sobre um embasamento gnássico-graníticomigmatíico Paleoproterozóico (Complexo Caicó) e migmatitos Arqueanos.

0 Complexo Caicó reúne ortognaisses tonalíticos-granodioríticos, ortognaisses maciços e migmatidos, com intercalações de metamáficas e metaultramáficas, de formações ferríferas bandadas (BIFs) e mármores, interpretadas como suítes magmáticas de arco magmático transamazônico com idades entre 2.3 e $2.15 \mathrm{Ga}$ (Jardim de Sá, 1994; Ferreira, 1997; Santos et al., 1999; Ferreira \& Santos, 2000; Angelim et al., 2004).

0 Grupo Seridó reúne uma unidade litoestratigráfica basal com paragnaisses a biotita, epídoto e anfibólio denominada Formação Jucurutu; uma unidade intermediária denominada Formação Equador com quartzitos puros, micáceos ou feldspáticos, com intercalação de metaconglomerados monomíticos e polimíticos (Formação Parelhas de Ebert, 1970); e uma unidade superior dominantemente metapelítica com biotita xistos, intercalações de mármores, anfibolitos referida como Formação Seridó (Fig. 1).

São rochas de natureza plataformal marinha e turbidítica profunda submetidas a metamorfismo da fácies xisto verde a anfibolito, num regime de pressões intermediárias, e intrudidas por granitos sin a tarditectônicos (Ferreira \& Albuquerque, 1969; Jardim de Sá \& Salim, 1980; Jardim de Sá, 1984; Archanjo \& Salim, 1986; Ferreira, 1997; Ferreira \& Santos, 2000; Angelim et al., 2004).

Da Silva (1993) distinguiu no âmbito das rochas graníticas quatro tipos principais de granitos, denominados de GR-1 a GR4. 0 tipo GR-3 tem características geoquímicas de granitos do tipo $\mathrm{S}$, peraluminosos, ocorrendo na forma de pequenos stocks, sills e diques, com texturas variando de média a pegmatítica, as quais são utilizadas como critério na diferenciação das fácies GR-3a e GR-3b (Da Silva \& Guimarães, 1992; Da Silva, 1993). 
A fácies GR-3a é representada por granitos e granodioritos de grã média e a fáceis GR-3b é similar a granitos férteis, com textura grossa a pegmatítica com fenocristais de microclíneo pertítico, intercrescimento gráfico, além de granadas e turmalinas entre os acessórios mais comuns (Da Silva, 1993).

De acordo com Baumgartner et al. (2006) a idade de $570 \mathrm{Ma}$ para os granitos G3 (Jardim de Sá et al., 1986; Jardim de Sá, 1994) e de $528 \pm 12$ Ma para os granitos pegmatííicos do tipo GR3 (Da Silva, 1993) indicaria um lapso excessivamente longo de tempo entre os processos de formação dessas rochas e os pegmatitos mineralizados ( $509 \pm 2,9 \mathrm{Ma}$ e $515 \pm 1,1 \mathrm{Ma}$, segundo Baumgartner et al., 2006) o que inviabilizaria a interpretação de que estes granitos seriam a rocha fonte dos pegmatitos mineralizados.

Segundo Beurlen et al. (2008) não há registro de uma intrusão granítica única volumetricamente suficiente para justificar sua interpretação como fonte dos pegmatitos mineralizados, e a ocorrência de numerosas intrusões de granito pegmatítico e sua alta frequência no terreno faz supor que a PPB é constituída de pequenos campos de pegmatitos, cada qual com a sua própria fonte de material e distribuição zonal, em muitos locais com sobreposição.

Novas datações de granitos pegmatíticos (granito Picuí), segundo Beurlen et al. (2009), com idades U-Th-Pb de $520 \pm$ $10 \mathrm{Ma}$, ainda estariam de acordo com uma relação genética e cronológica destes granitos pegmatíticos (GR3) com os pegmatitos mineralizados.

Os pegmatitos da PPB foram classificados em dois principais tipos, denominados de homogêneos e heterogêneos (Johnston Jr., 1945). Os homogêneos não exibem zoneamento interno e sua mineralogia é simples. Os heterogêneos são normalmente mineralizados, exibem zoneamento interno e sua mineralogia é por vezes bastante diversificada. Da Silva (1993) apresenta uma extensa revisão dos minerais de pegmatitos da PPB.

As coberturas fanerozóicas estão representadas na área de estudo por arenitos terciários da Formação Serra dos Martins e pelas coberturas arenosas e argilo-arenosas elúvio-coluviais quaternárias.

\section{GRANITOS E PEGMATITOS ASSOCIADOS}

Os granitos pegmatíticos observados em campo constituem conjuntos de rochas leucocráticas, porfiríticas (Fig. 2A) compostas essencialmente por quartzo, plagioclásios microclíneo, muscovita, por vezes com biotitas, além de granadas e turmalina negra. Localmente apresentam bandamento magmático (Fig. 2B) com leitos de granulometria mais fina ricos em cristais de grana- das e/ou turmalina negra alternados com bandas mais espessas quartzo-feldspáticas (Fig. 2B).

As dimensões de alguns desses corpos variam de $0,3 \mathrm{~km}^{2}$ a $0,8 \mathrm{~km}^{2}$. No entanto, sua frequência e a proximidade relativa entre os mesmos levam a supor que as dimensões em profundidade sejam maiores do que as atualmente expostas. São corpos com formas sub-arredondadas a elípticas (Figs. 2C, 2D, 2E, 2F e $2 \mathrm{G}$ ), acompanhando a direção geral NE-SW da foliação regional S3. Um único granito pegmatítico conhecido por Boqueirãozinho encontra-se sotoposto a coberturas lateritizadas e totalmente caulinizado (Fig. 2G).

Os pegmatitos são na sua maioria homogêneos, caulinizados (Fig. 2H) e ocorrem dominantemente encaixados nos quartzitos da Formação Equador. Têm morfologia marcantemente tabular e dimensões aflorantes que variam de 1 a 30 metros de largura, com extensões de 50 metros a mais de $3 \mathrm{~km}$, como observado em pegmatito situado ao sul da cidade do Junco do Seridó (Fig. 2l).

No pediplano regional, a oeste da cidade de Parelhas, enxames de pegmatitos estão alojados em biotita xistos da Formação Seridó na forma de corpos tabulares, subhorizontais (Fig. 2J) ou subverticais, truncando a foliação regional S3 destas rochas (Fig. 2K). No flanco oeste da Serra das Queimadas são observados muitos blocos de granito pegmatíitico junto aos quartzitos da Formação Equador (Fig. 2L).

\section{MATERIAIS E MÉTODOS}

\section{Características e correções dos dados geofísicos}

Os dados aerogamaespectrométricos utilizados neste estudo são provenientes do Projeto Seridó, executado na década de 1970 pela LASA - Engenharia e Prospecções S.A. para a Companhia de Pesquisa de Recursos Minerais - CPRM, sob convênio com o Departamento Nacional da Produção Mineral - DNPM e a Comissão Nacional de Energia Nuclear - CNEN (LASA, 1974; CPRM, 1994). 0 Projeto Seridó envolveu $28.000 \mathrm{~km}$ de perfis na direção $\mathrm{E}-\mathrm{W}$, com espaçamento de $1 \mathrm{~km}$ entre as linhas de voo e linhas de controle de direção N-S afastadas de $20 \mathrm{~km}$. A amostragem ao longo das linhas de voo foi de 135 metros e 0 aerolevantamento cobriu uma área aproximada de $25.000 \mathrm{~km}^{2}$ (LASA, 1974).

Os arquivos digitais utilizados foram gerados na CPRM a partir da digitalização de pontos de cada linha de voo sobre cartas na escala 1:50.000 (CPRM, 2008).

No aerolevantamento foi utilizado o gamaespectrômetro modelo EXPLORANIUM DiGRS-2000, com unidade detectora com 


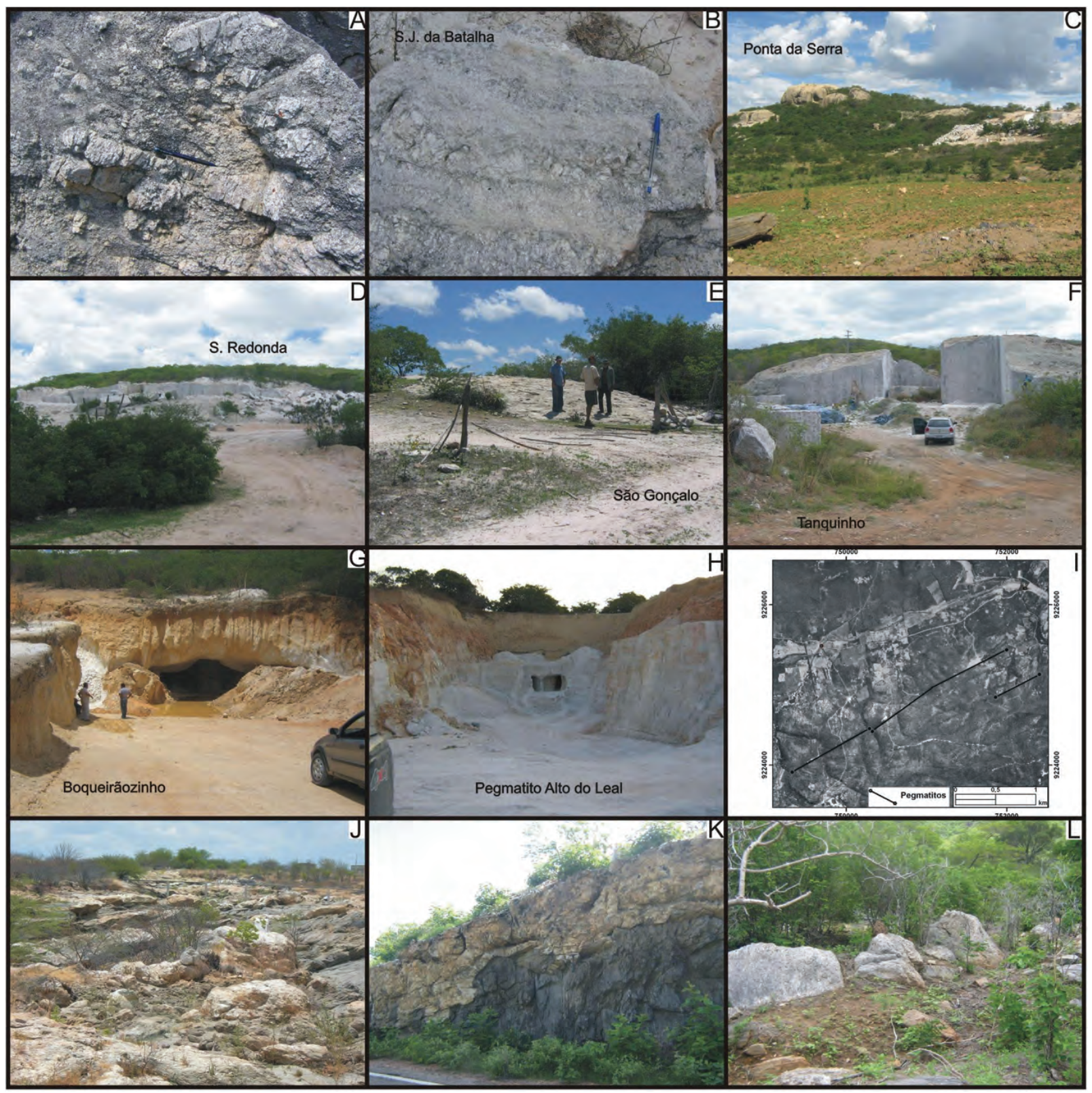

Figura 2 - (A) aspectos da textura megaporfíritica do granito Galo Branco; (B) bandamento magmático em granito próximo à vila de São José da Batalha; (C) aspectos geomorfológicos do granito Ponta da Serra (SS093); (D) granito Serra Redonda (SS121); (E) granito São Gonçalo (SS090); (F) frente de lavra do granito Tanquinho (SS033); (G) granito Boqueirãozinho (SS057), caulinizado sotoposto a coberturas lateritizadas; (H) pegmatito Alto do Leal situado ao sul do granito Serra Redonda (SS121); (I) pegmatito localizado a sudoeste da cidade de Junco do Seridó; (J) enxames de diques pegmatíticos subhorizontais observados na estrada Parelhas Equador; (K) pegmatito subhorizontal localizado na estrada Parelhas - Equador; (L) blocos e matacões de granito no flanco ocidental da Serra das Queimadas.

três conjuntos de cristais de iodeto de sódio ativado a tálio, totalizando 1012,5 polegadas cúbicas, com tempo de integração de 2 segundos (LASA, 1974). Detalhes do aerolevantamento e das correções básicas dos dados podem ser encontrados em LASA (1974). Os dados originalmente obtidos em contagens por segundo (cps) não foram retrocalibrados para concentrações de urânio (eU) e tório (eTh) em ppm e potássio (K) em porcentagem (CPRM, 1994; BARMP, 1997).

De posse da base de dados, executou-se o recorte para 0 polígono da área de estudo e a reprojeção para o sistema Universal Transversa de Mercator - UTM, Zona 24S. Fez-se uma avaliação das estatísticas (média, variância, desvio padrão) de cada 
canal (U, Th, K) e a inspeção visual dos dados ao longo das linhas de voo. Os valores negativos encontrados, que provavelmente se devem a problemas de leituras e correção do background (Pires, 1995), foram corrigidos adicionando-se uma constante para cada grupo de dados, de modo a elevar os valores finais de um décimo, evitando-se, com isto, operações com valores nulos (Ferreira et al., 2009). Em seguida foram geradas malhas regulares de $U$, The K com células de 500 metros, utilizando um algoritmo de mínima curvatura (Briggs, 1974).

Com base nas malhas foi executado o micronivelamento para filtrar alguns artefatos remanescentes nos dados, utilizando-se 0 método proposto por Minty (1997) e adaptado por Blum (1999). Por fim, foram produzidas as imagens geofísicas dos canais U Th e K, além das razões $\mathrm{U} / \mathrm{Th}, \mathrm{U} / \mathrm{K}$ e Th/K.

0 levantamento terrestre foi executado com 0 gamaespectrômetro portátil GS-512, fabricado pela Geofyzika (República Tcheca) e comercializado pela Scintrex, pertencente ao Laboratório de Pesquisas em Geofísica Aplicada - LPGA, da Universidade Federal do Paraná - UFPR.

0 GS-512 opera com 512 canais no intervalo de 0,1 a 3 Mev e as leituras obtidas em contagens por segundo (cps) foram automaticamente convertidas para concentrações de equivalentes de urânio (eU), de tório (eTh) e porcentagens de potássio (K), de acordo com calibração realizada anteriormente no Instituto de Radioproteção e Dosimetria (IRD) da Comissão Nacional de Energia Nuclear (CNEN). Procedimentos e detalhes dessa calibração e conversão dos dados são descritos em Becegato \& Ferreira (2005).

As leituras, variando de uma a três em cada ponto, foram obtidas com tempo de integração de 3 minutos. No granito Galo Branco foi definida uma malha de $50 \times 20$ metros para obtenção das medidas, totalizando 120 registros.

Os dados da malha foram interpolados pelo método da curvatura mínima (Briggs, 1974) para células de 10 metros, correspondendo a 1/5 do espaçamento máximo das amostras. Depois foi feita a análise visual e estatística (média, mediana, variância e desvio padrão) de cada conjunto de dados, observando-se a inexistência de valores negativos ou nulos. Em seguida, gerou-se as imagens das razões eU/eTh, eU/K e eTh/K. Todos os produtos gerados foram incorporados a uma única base de dados espaciais.

As imagens aerogamaespectrométricas foram sobrepostas ao modelo digital de elevação gerado a partir de dados da missão Shuttle Radar Topography Mission (SRTM). No caso do granito Galo Branco utilizou-se uma imagem pancromática do sensor orbital QuickBird com resolução espacial 0,65 cm, para apoiar o mapeamento geológico, o posicionamento da malha e a sobreposição de resultados da gama terrestre. A cena foi georreferenciada com base em pontos coletados com GPS e pontos extraídos da base cartográfica do projeto.

Após aquisição das medidas radiométricas de campo foram selecionadas algumas amostras para posterior análise dos respectivos teores de urânio, tório e potássio em laboratório. Essas amostras foram britadas, quarteadas, moídas, acondicionadas e lacradas até a execução da dosagem radiométrica por espectrometria gama de alta resolução (IPEN, 2006) no Instituto de Pesquisas Energéticas e Nucleares (IPEN) e da determinação química por Inductively Coupled Plasma Mass Spectroscopy (ICP-MS) no Instituto de Geociências da Universidade Estadual de Campinas (IG/UNICAMP). As amostras para análise por ICP-MS foram antes secadas, pesadas e diluídas em solução ácida $\left(\mathrm{HNO}_{3}\right.$ e HF) em bombas acondicionadas em autoclaves em estufa, durante 48 horas à temperatura de $150^{\circ} \mathrm{C}$. As alíquotas necessárias em cada método são 250 gramas e 1 grama de amostra, respectivamente.

\section{RESULTADOS E DISCUSSÃO Aerogamaespectrometria}

A Figura 3A mostra as imagens dos canais do potássio, do tório, do urânio, juntamente com a imagem ternária dos três canais. As razões entre os canais eU/eTh é apresentada na Figura 3B e entre os canais eTh/K na Figura 3C. 0 Mapa Geológico do Brasil ao Milionésimo, Folha Jaguaribe (SB.24) é mostrado na Figura 3D. Nas figuras estão indicadas as siglas dos principais corpos graníticos observados em campo. Também estão assinalados pontos correspondentes a pegmatitos e granitos pegmatíticos de menor porte. Cabe destacar que nem todos os corpos pegmatíticos existentes foram detectados pela aerogamaespectrometria, em função da reduzida resolução espacial dos dados, enquanto outras anomalias por ela indicadas não puderam ser verificadas por dificuldades de acesso.

A Figura 3A sintetiza os resultados dos canais individuais, destacando, principalmente, a diferença de comportamento gamaespectrométrico das litologias das regiões ao norte e ao sul das cidades de Equador e do Junco do Seridó (Fig. 3D).

Na imagem ternária da Figura 3A, o potássio exibe na região norte valores elevados, em tons intensos de vermelho, relacionados às áreas de ocorrência dos quartzitos da Formação Equador, metaconglomerados da Formação Parelhas e paragnaisses da Formação Jucurutu (Figs. 3A e 3D). São rochas quartzo-feldspáticas e gnáissicas ricas em feldspatos e muscovitas, hospedeiras de enxames de pegmatitos e granitos pegmatíticos também ricos nestas fases minerais. 


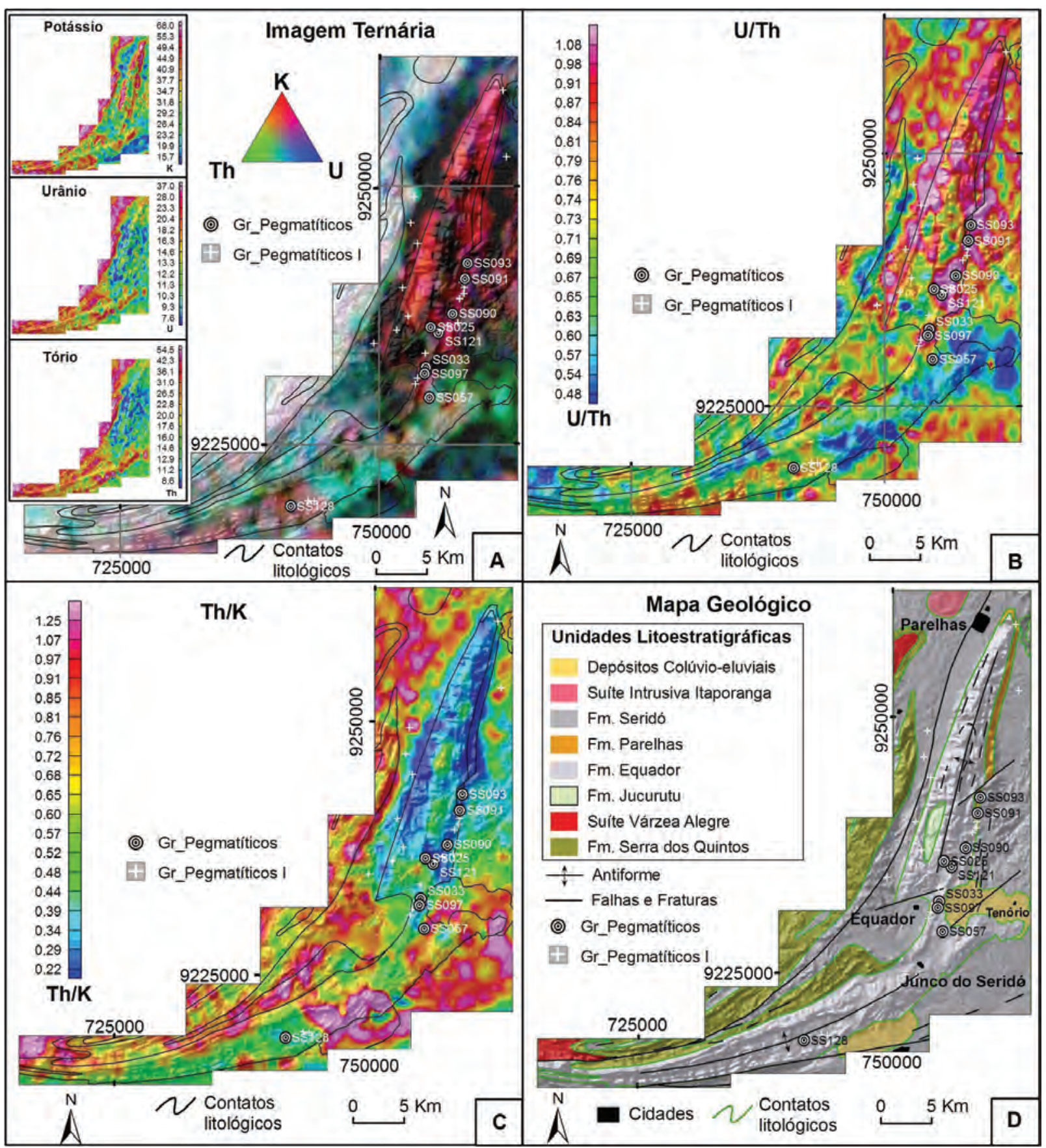

Figura 3 - Imagem ternária e dos canais individuais eU, eTh e K (3A); da razão eU/eTh (3B); da razão eTh/K (3C) e o mapa geológico regional (3D) adaptado de Angelim et al. (2004).

Na região sul, o canal do potássio caracteriza-se por valores mais baixos, que aparecem em tons róseos e avermelhados, claros, na continuidade S-SW dos quartzitos da Formação Equador (Figs. 3A e 3D), revelando diferenças de composição destas rochas para com suas congêneres da região norte. Os quartzitos da região sul são menos micacéos e mais grosseiros e os granitos pegmatíticos, nesta mesma região, são bem mais escassos. Nos locais onde são observados tons fortes de verde (Fig. 3A), a sudoeste da cidade de Junco do Seridó (Fig. 3D), foram encontrados metaconglomerados ricos em minerais 
toríferos (Silva, 2009, Silva et al., 2010).

A Figura 3A mostra que a análise das imagens dos canais individuais e da imagem ternária não possibilita individualizar as Formações Jucurutu e Parelhas da Formação Equador devido à similaridade de suas assinaturas gamaespectrométricas elevadas no canal do potássio, e baixas nos canais do urânio e do tório. Apesar disto, tanto as imagens individuais como as razões eU/ eTh e eTh/K (Figs. 3B e 3C) mostram claramente que é possível separar os quartzitos da região sul daqueles da região norte.

Estes resultados são importantes do ponto de vista do mapeamento geológico e da exploração mineral, pois denotam que 0 uso, por exemplo, de rotinas automáticas para classificação e individualização de padrões de rochas com base nos canais individuais deve ser visto com cautela, dada a possibilidade de produzirem resultados geológicos inconsistentes. 0 motivo para isso é a possível coincidência de intervalos de valores gamaespectrométricos decorrentes das características composicionais inerentes ou superimpostas, e muitas vezes similares, de muitas rochas, solos e coberturas superficiais.

A imagem da razão eU/eTh (Fig. 3B) realça a discriminação das litologias das regiões Norte e Sul. Entretanto, e diferentemente dos canais individuais, ela realça na região norte vários tratos anômalos no flanco leste da Serra das Queimadas, delimitando um trend onde foram encontrados granitos pegmatíticos desde Ponta da Serra (SS093) até Boqueirãozinho (SS057) (Figs. 3A, 3B, 3C e 3D).

Ainda nesta imagem (Fig. 3B), áreas e pontos isolados em tons róseos fortes a oeste da cidade de Parelhas (Fig. 3D), se relacionam, no pediplano regional e nos leitos de rios e riachos, a enxames de diques pegmatíticos, aplitos e veios de quartzo subhorizontais encaixados em biotita xistos da Formação Seridó (Fig. 2J).

Parte das anomalias situadas nas encostas e no sopé ocidental da Serra das Queimadas a sudoeste da cidade de PareIhas (Figs. 3A, 3B e 3D) podem resultar das coberturas colúvioeluviais inconsolidadas espessas, areias grossas, blocos e matacões rolados de rocha granítica.

A razão eTh/K exibe baixos valores para litologias da região norte (gnaisses, quartzitos, metaconglomerados e granitos) e altas contagens para as rochas (quartzitos e coberturas) das regiões sul, sudeste e sudoeste do Junco do Seridó (Figs. 3A, 3C e 3D). Áreas anômalas em tório foram ainda identificadas ao longo dos rios a oeste e sudoeste de Parelhas (Silva, 2009; Silva et al., 2010), em locais distintos das anomalias da razão eU/eTh (Figs. 3B e 3C).

As três áreas com anomalias de tório em tons de verde
(Fig. 3A) e róseos fortes (Fig. 3C) localizadas sobre os quartzitos da região a sudoeste de Junco do Seridó (Fig. 3D) correspondem a metarenitos grossos e metaconglomerados ricos em minerais pesados que afloram nas serras locais. Outras anomalias realçadas pela razão $\mathrm{eTh} / \mathrm{K}$ no pedipano regional refletem concentrações de minerais toríferos provenientes destas rochas (Silva, 2009). Para este autor, parte dos minerais removidos destas serras foram carreados para esta região, enquanto outras parcelas transportadas para sudeste da cidade de Junco do Seridó (Figs. $3 \mathrm{C}$ e 3D), que resultaram na profusão de anomalias sobre coberturas colúvio-eluviais e aluviais nesses locais.

\section{Resultados de laboratório}

Neste item é feita uma análise baseada nas medidas de campo e nas determinações em laboratório das concentrações de urânio, tório e potássio em amostras de granitos pegmatíticos da área de estudo. Para efeito de comparação e subsídio a essa análise são apresentados na Tabela 1 valores extraídos da literatura referentes às concentrações de radioelementos em vários tipos de rochas ígneas. Também constam os valores das médias, dos desvios padrão e dos coeficientes de variação ou de dispersão dos dados. Os dados da Tabela 1 mostram variações na concentração de todos os radioelementos e também sobreposição de intervalos de variação de teores para todas as rochas ígneas.

As concentrações de potássio variam entre 0,1\% e 7,6\%, com média 3,2\% e o menor coeficiente de variação que é de 0,8 . A amplitude de variação das concentrações de urânio e tório é maior que a do potássio. Para urânio ela está entre 0,1ppm e 30 ppm e entre 0,1 ppm e 253,1 ppm para tório. As concentrações médias são de 5,7 ppm para urânio e de 31,6 ppm para o tório, cujo valor está muito acima da concentração média na crosta terrestre que varia entre 10,7 e 17 ppm nas rochas graníticas em geral (Heier \& Rhodes, 1966). 0 tório ainda apresenta maior coeficiente de variação $(2,2)$ que 0 urânio $(1,5)$.

$\mathrm{Na}$ Tabela 2 constam os resultados da espectrometria gama de alta resolução (IPEN), das determinações semiquantitativas por ICP-MS e das medidas de campo. Também estão as siglas dos pontos, o número de leituras realizadas em campo, o valor mínimo, o máximo e a média. Nas últimas três linhas da Tabela 2 estão os valores das médias, dos desvios padrão e dos coeficientes de variação de cada radioelemento. Os resultados da espectrometria gama de alta resolução (IPEN) fornecidos em Bq/Kg (Bequerel por quilograma) foram convertidos para ppm, utilizando a tabela de conversão do IAEA (2003).

Os resultados da Tabela 2 mostram que a concentração de urânio varia entre 0,47 ppm e 7,8 ppm, a de tório varia entre 
Tabela 1 - Concentração média de radioelementos em rochas ígneas.

\begin{tabular}{|c|c|c|c|c|}
\hline Tipologia & $\mathrm{U}(\mathrm{ppm})$ & Th $(\mathrm{ppm})$ & $\mathrm{K} \%$ & Fonte \\
\hline Granitóides & $0,4-7,8(3,3)$ & $2,3-45,0(16,0)$ & $0,3-4,5(2,4)$ & Dickson \& Scott (1997) \\
\hline Granitos, riolitos, etc, & 4,5 & 15,0 & - & Boyle (1982) \\
\hline Ácida Intrusiva & $0,1-30,0(4,5)$ & $0,1-253,1(5,7)$ & $0,1-7,6(3,4)$ & Kileen (1979) \\
\hline Pegmatitos & $0,3-1,0(0,7)$ & $0,3-9,6(2,0)$ & $2,6-5,5(3,7)$ & Dickson \& Scott (1997) \\
\hline Aplitos & $1,0-8,0(3,3)$ & $3,0-20,0(7,0)$ & $0,6-4,0(2,4)$ & Dickson \& Scott (1997) \\
\hline Ácida Extrusiva & $0,8-16,4(4,1)$ & $1,1-41,0(11,9)$ & $1,0-6,2(3,1)$ & Kileen (1979) \\
\hline Quartzo-feldspática porfiŕtica & $1,3-2,9(1,7)$ & $6,0-14,0(13,0)$ & $1,0-5,0(2,9)$ & Dickson \& Scott (1997) \\
\hline Média (Md) & 5,7 & 31,6 & 3,2 & \\
\hline Desvio padrão (Dp) & 8,7 & 68,2 & 2,6 & \\
\hline Coeficiente de variação (Cv) & 1,5 & 2,2 & 0,8 & \\
\hline
\end{tabular}

Tabela 2 - Resultados das determinações analíticas (ICP), da dosimetria para urânio, tório e potássio (IPEN) e das medidas gamaespectrométricas de campo (CAMPO) de 6 (seis) amostras de granitos pegmatíticos.

\begin{tabular}{|c|c|c|c|c|c|c|c|c|c|}
\hline \multirow{2}{*}{ Amostras } & \multicolumn{3}{|c|}{ U (ppm) } & \multicolumn{3}{|c|}{ Th (ppm) } & \multicolumn{3}{|c|}{$\mathrm{K} \%$} \\
\hline & $\overline{I C P}$ & IPEN & CAMPO & $\overline{I C P}$ & IPEN & CAMPO & ICP & IPEN & CAMPO \\
\hline SS093 & 1,05 & 2,40 & $3,3-3,7(3,50)$ & 1,00 & 1,65 & $15,2-17,7(16,45)$ & 5,24 & 4,32 & $4,9-5,0(4,95)$ \\
\hline SS121 & 1,87 & 3,50 & $4,0-7,8(5,83)$ & 1,90 & 3,27 & $16,6-21,0(19,43)$ & 2,75 & 2,36 & $3,1-3,8(3,53)$ \\
\hline SS128 & 6,23 & 4,86 & 7,5 & 0,73 & 1,10 & 1,2 & 3,37 & 3,00 & 3,9 \\
\hline GB014 & 0,47 & 3,50 & 1,3 & 0,40 & 0,25 & 1,3 & 2,63 & 2,47 & 3,4 \\
\hline SS097 & 1,66 & - & $3,4-5,8(4,40)$ & 0,58 & - & $0,1-4,4(1,60)$ & 3,69 & - & $2,0-4,3(3,10)$ \\
\hline SS091 & 6,47 & - & $4,1-7,6(5,96)$ & 0,74 & - & $17,0-19,6(18,10)$ & 2,29 & - & $3,4-4,2(3,73)$ \\
\hline Md & \multicolumn{3}{|c|}{3,9} & \multicolumn{3}{|c|}{8,4} & \multicolumn{3}{|c|}{3,7} \\
\hline Dp & \multicolumn{3}{|c|}{2,4} & \multicolumn{3}{|r|}{9,0} & \multicolumn{3}{|c|}{0,7} \\
\hline $\mathrm{CV}$ & \multicolumn{3}{|c|}{0,6} & \multicolumn{3}{|r|}{1,1} & \multicolumn{3}{|c|}{0,2} \\
\hline
\end{tabular}

0,1 ppm e 21 ppm e a do potássio varia entre $2 \%$ e 5,24\%. Comparativamente, revelam-se dentro dos intervalos de variação das respectivas concentrações de urânio (01ppm a 30 ppm), de tório (0,1 ppm a 253,1 ppm) e de potássio (0,1\%) encontrados para as rochas ígneas em geral (Tab. 1). Também as médias de 3,9 ppm para urânio, de 8,4 ppm para tório e de 3,7\% para o potássio (Tab. 2) estão abaixo ou, como no caso do potássio um pouco acima, das médias apontadas na literatura para estas rochas (Tab. 1)

Na Tabela 2 também pode-se notar que quase todas as medidas de campo, notadamente para urânio e tório apresentam valores acima das dosagens e determinações de laboratório.

0 potássio apresenta 0 menor intervalo de variação entre os três radioelementos. Uma única amostra (SS093) apresenta valor fornecido pela análise por ICP-MS de 5,24 ppm, acima dos demais valores da espectrometria gama e de medidas de campo. Os teores de potássio entre $2 \%$ e 5,24\% e média de 3,3\% (Tab. 2) encontram-se no intervalo de variação de 0,1\% a 7,6\% e média de 3,4\% das concentrações nas rochas ígneas da Tabela 1. A concentração média do potássio na crosta terrestre é de 2,35\% (Dickson \& Scott, 1997).

Contrariamente ao observado em termos de valores absolutos, os coeficientes de variação dos três radioelementos (Tab. 2) estão todos abaixo daqueles indicados na literatura (Tab. 1). De modo similar, em ordem decrescente, ele é maior para 0 tório, seguido do urânio e, por último, do potássio.

Esta análise indica que as diferenças de valores absolutos menores para urânio e tório das análises ICP-MS (menor alíquota), para a espectrometria de alta resolução (IPEN) (alíquota intermediária), e destas para as medidas de campo, demonstram que existe uma certa dependência dos métodos de laboratório em relação às alíquotas analisadas, as quais podem, por sua vez, serem afetadas por heterogeneidades de conteúdo e de concentração de minerais acessórios na rocha pegmatítica analisada. 
Os resultados também demonstram que para o potássio, essa dependência é minimizada pelo fato dele integrar as fases minerais (micas, feldspatos) presentes em maior quantidade e homogeneidade na rocha pegmatítica, em relação aos acessórios monazita, zircão, torita, entre outros minerais fontes de radiação de urânio e tório.

Estudos de calibração e de certificação de laboratórios realizados em vários países com amostra de pegmatito, mostraram uma variada gama de resultados para elementos maiores, menores e traço entre os 67 laboratórios participantes do evento GeoPT23 (Webb et al., 2008). Os resultados do GeoPT23A apontam para a dificuldade natural de se analisar rochas de composição pegmatítica, com certa imprevisibilidade de valores diante das alíquotas analisadas por métodos diferentes em um mesmo laboratório ou em laboratórios distintos.

Segundo Webb et al. (2008), a dispersão pouco usual dos resultados pode advir de diversos fatores. Citam, entre outros, a concentração próxima dos limites de detecção, e 0 conteúdo de minerais acessórios como columbita, tantalita e cassiterita, cada qual com concentrações elevadas e variadas de elementos traço, propiciando o aparecimento do efeito pepita, principalmente quando são analisadas alíquotas reduzidas.

Desse modo, entende-se que os resultados obtidos neste estudo são coerentes com a variabilidade e padrões dos radioelementos nas rochas ígneas indicadas na literatura, e que os valores de concentração de urânio e tório com frequência menores nos resultados de laboratório em relação àqueles das medidas de campo decorrem da variação modal-mineralógica de minerais acessórios nos granitos pegmatíiticos.

\section{GRANITO GALO BRANCO}

0 granito Galo Branco está situado a cerca de $3 \mathrm{~km}$ a Leste da cidade de Equador/RN (Fig. 4). Constitui um corpo alongado na direção NNE com maior área de exposição na Fazenda Galo Branco, onde é lavrado como rocha ornamental, comercialmente conhecida como "Star White".

\section{Aspectos geológicos}

A Figura 5 apresenta aspectos geomorfológicos, geológicos, texturais e petrográficos do granito Galo Branco. Este granito está encaixado nos quartzitos da Formação Equador, cuja foliação regional $S_{2} / / S_{3}$ de mergulhos baixos, geomorfologicamente propicia o seu recobrimento nas porções sul e oeste da área de estudo (Figs. 5A, 5B, 5C e 5D). Foliação e aspectos do microrelevo são sugestivos de que os quartzitos centrais constituam localmente megaenclaves sobrejacentes ao granito (Figs. 4 e 5J).
Na área da lavra, e a noroeste dela, são observados enclaves, de pequeno e grande porte, de biotita xistos e quartzitos, exibindo contatos bruscos (Fig. 5F), que em conjunto com apófises graníticas laterais ao corpo central indicam seu caráter intrusivo (Fig. 4). Na direção S-SW, estas apófises, com suas geometrias ligeiramente dômicas, levaram a inferir a continuidade do granito como um corpo único (Fig. 4). Outros corpos menores de pegmatitos, aplitos e de veios de quartzo ocorrem encaixados em fraturas nos quartzitos (Fig. 4).

São todas rochas de coloração clara, ricas em feldspatos, muscovitas e quartzo, com textura grossa característica (Fig. 5E). 0 contato dos pegmatitos com os quartzitos é brusco, da mesma forma como nos enclaves destes últimos no granito (Fig. 5F). Os pegmatitos no entorno do granito Galo Branco são homogêneos, caulinizados e guardam estreita relação espacial com este, de onde migram para o topo e para as porções laterais, encaixando nos quartzitos sobrejacentes. Truncam as foliações $\mathrm{S}_{2}$ e $\mathrm{S}_{3}$ regionais com mergulhos subverticais e direções NNE (Fig. 4). 0 contato do granito com os quartzitos na área da mina está encoberto pelas coberturas residuais.

0 granito exibe textura pegmatítica ou fanerítica isogranular grossa (Figs. 5E e 5G). A análise petrográfica de amostra coletada em porção mais fina da rocha revelou quartzo (40\%), feldspato alcalino (ortoclásio - 20\% e microclínio - 10\%), plagioclásio (10\%), muscovita (15\%), illita/sericita (5\%), além de zircão, monazita, apatita e opacos $(<2 \%)$.

No granito Galo Branco também ocorrem os minerais torbernita/metatorbernita, além de torita, uraninita e columbita (Beurlen, com. verbal). Concentrações de torbernita foram vistas localizadamente, ao passo que os demais minerais não foram observados em campo ou em lâmina delgada. A análise de fragmentos de micas por difração de raios $X$ confirmou a presença de torbernita, $\mathrm{e}$ na microscopia de varredura eletrônica (MEV-EDS) identificou-se nesta fase mineral teores variando entre 36\% e 75\% de urânio. Também foram determinados teores entre $8 \%$ e $50 \%$ de tório, entre $28 \%$ e $35 \%$ de ítrio, entre $3 \%$ e 3,3\% de neodímio, entre $22 \%$ e $44 \%$ de fósforo em monazita e entre $1,6 \%$ e 2,4\% de háfnio e 39\% e 65\% de zircônio em zircão.

A fase da illita/sericita foi identificada em campo por meio da espectroscopia de reflectância, conforme possibilidades já demonstradas por Hauff et al. (1991) e Zhang et al. (2001). Esta fase apresenta feição de absorção espectral profunda e bem definida, centrada em 2204 nm, devido à ligação AL-OH, e outra em torno de $1912 \mathrm{~nm}$ devido à presença de água na fase mineral (Fig. 5L). 0 cálculo do grau de ordenamento estrutural obtido a partir do espectro de reflectância, segundo proposto por (Pontual 

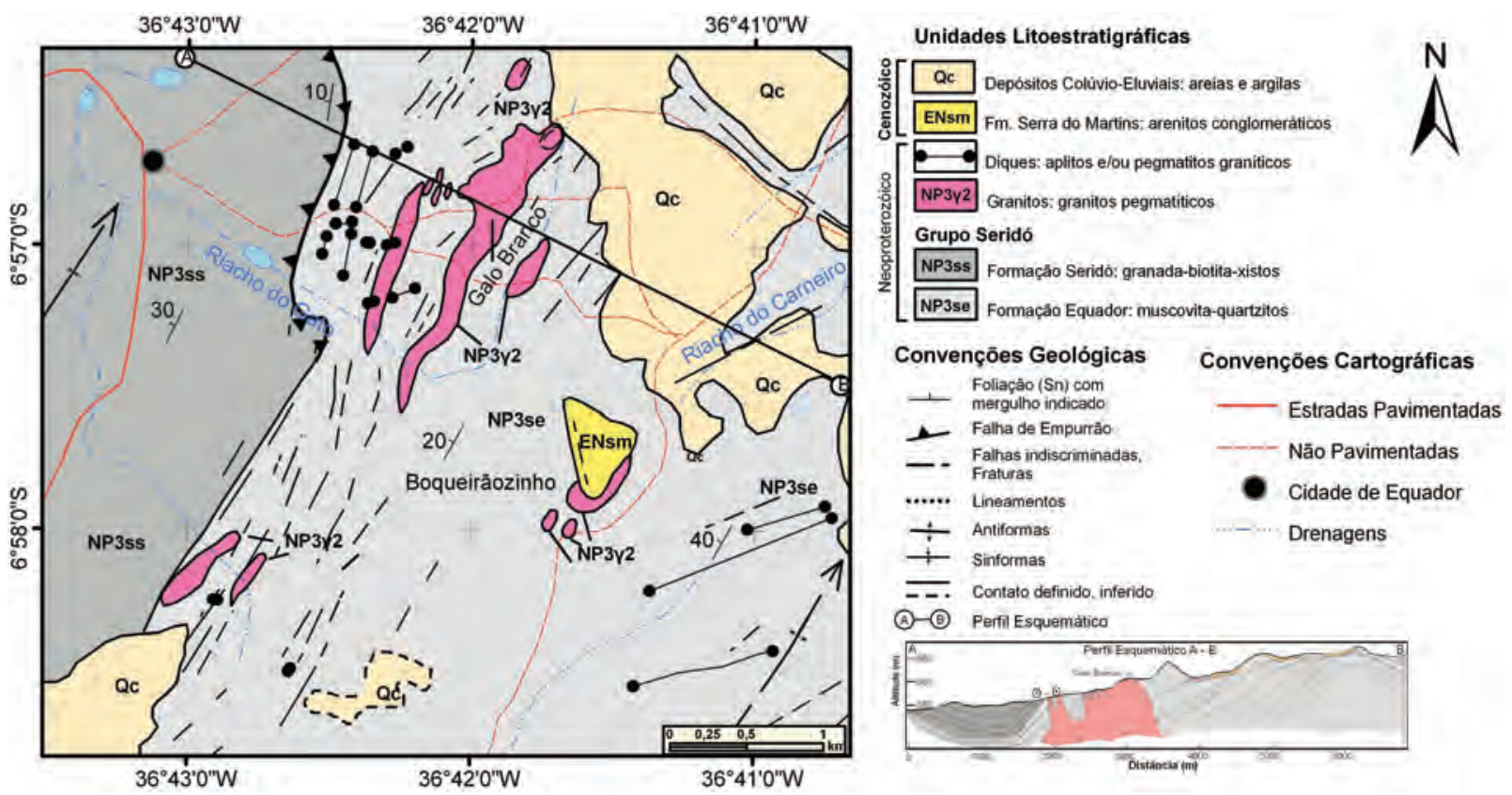

Figura 4 - Croqui geológico dos arredores do granito Galo Branco. Nomenclatura litoestratigráfica a partir de Angelim et al., 2004.

et al., 1997), mostrou que se trata de illita/sericita de alto grau de ordenamento estrutural, o que segundo Srodon \& Eberl (1984) indicaria que sua formação se deu em temperaturas mais elevadas, provavelmente associada com alteração hidrotermal da rocha (Fig. 5l).

\section{Gamaespectrometria terrestre}

A Figura 6 mostra as imagens do potássio (A), do urânio (B), do tório $(C)$ e da contagem total (D), sobrepostas à imagem orbital do sensor QuickBird. Em verde estão indicados os contatos inferidos entre os quartzitos e o granito por toda extensão oeste, sudoeste e leste. As coberturas residuais ocorrem preferencialmente a NE e NW da área de maior exposição do granito. A SSW do granito estão assinalados diques de pegmatitos.

As coberturas arenosas residuais (média a grossa) e coluviais mais grossa (cascalheiras) não foram individualizadas na malha do levantamento, mas suas espessuras foram estimadas entre $5 \mathrm{~cm}$ e $20 \mathrm{~cm}$. Elas espessam na direção NNE, SE e NNW (Figs. 6A, 6B, 6C e 6D). As coberturas residuais dos quartzitos apresentam cores amareladas a avermelhadas, com certa fração argilosa, e de coloração esbranquiçada quando oriunda e/ou sobrepostas ao granito, nesses casos, de grã ainda mais grossa.

As coberturas residuais provocam uma atenuação geral na intensidade da radiação sobre o granito subjacente. Se por um lado esse efeito atenuador dificulta o zoneamento gamaespectro- métrico de uma área maior do granito, e com maior detalhe, por outro, indica que alterações na natureza e intensidade do sinal da radiação no granito advém de heterogeneidades modal-mineralógicas desta rocha.

A imagem do potássio da Figura 6 A fornece bom resultado para o mapeamento do granito. Nesta imagem tem destaque a parte central do corpo aflorante com os valores mais elevados de potássio e os contatos aproximados com os quartzitos ao sul e a oeste.

A presença das coberturas arenosas, cujo espessamento ocorre na direção geral NNE, pode ser constatada através da diminuição lateral gradativa do sinal na imagem do potássio nesta direção. A imagem mostra que os teores mais baixos relacionamse aos quartzitos, os intermediários com as coberturas arenosas e os mais elevados com o granito. A assinatura gamaespectrométrica do potássio nos pegmatitos do sul (Fig. 6) confundese com a dos quartzitos, todos eles em tons de verde claro.

A imagem do urânio da Figura 6B exibe valores elevados no granito, em correspondência à mesma área do potássio. Entretanto, a anomalia é mais concentrada e melhor definida do que neste radioelemento. São pequenas manchas concentradas sobre a maior parcela de rocha fresca aflorante. Há pequena anomalia localizada ao norte, onde também aflora granito pegmatítico. As coberturas arenosas, os quartzitos e diques de pegmatitos apresentam valores menores para 0 urânio. 


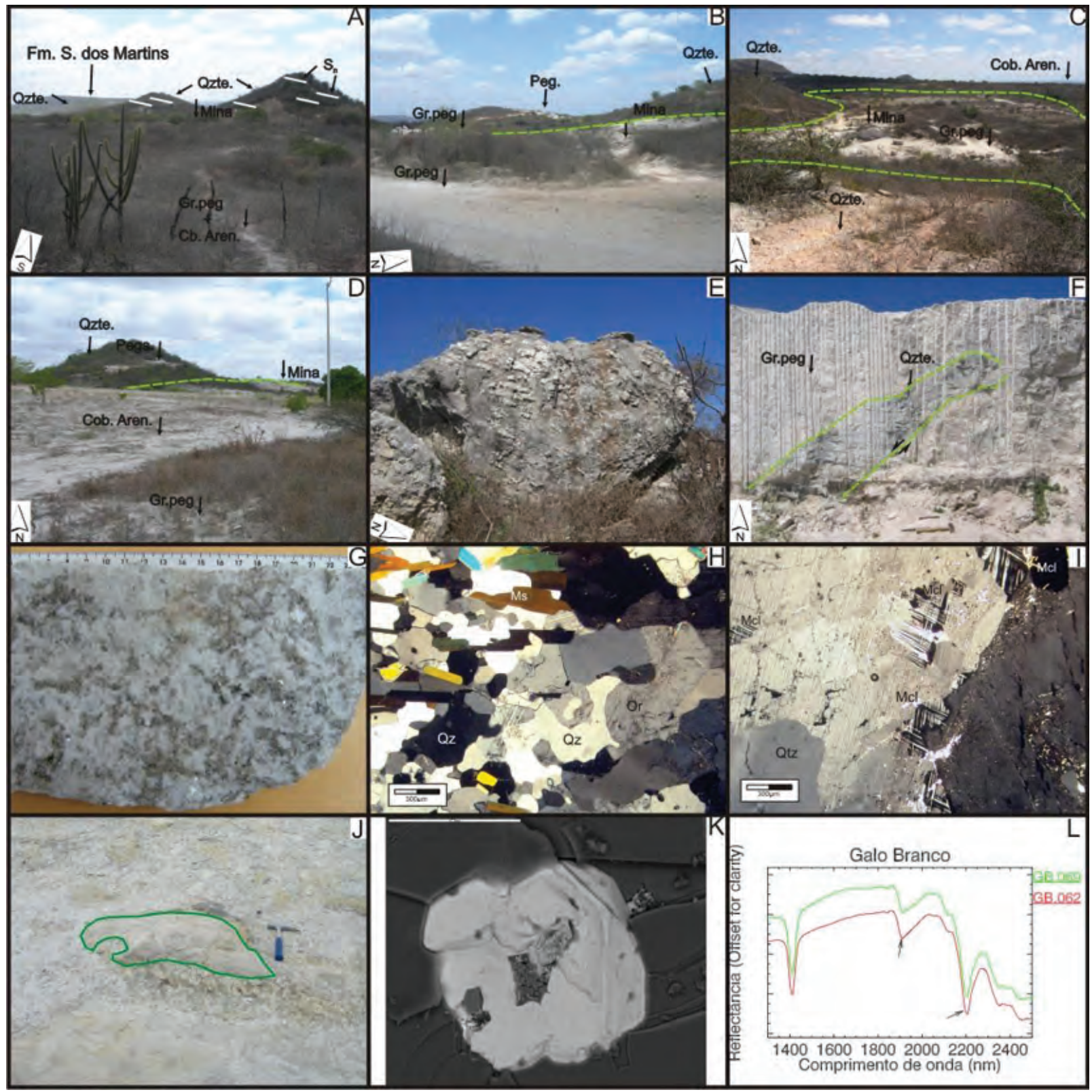

Figura 5 - (A) vista de norte para sul com indicação do local da mina e caimento geral para oeste da foliação regional S2; (B) visada de leste para oeste com indicação aproximada da zona de contato granito-quartzitos; $(C)$ visada de sul para norte do local da mina, do contato aproximado granito-quartzitos e das coberturas residuais; (D) visada SW-NE com indicação da zona de contato; (E) aspectos da textura pegmatítica do granito; (F) enclave de quartzito com indicador cinemático (sinistral); (G) textura mais fina no granito Galo Branco; $(\mathrm{H})$ aspectos petrográficos do contato granito-quartzito; (I) minerais principais do granito (quartzo, microclínio, ortoclásio, sericita); (J) aspectos e relações de microrelevo granito-quartzito; (K) inclusão de monazita mostrando borda de reação com a mica; (L) espectros de referência e da illita/sericita do granito Galo Branco.

A imagem do tório da Figura $6 \mathrm{C}$ destaca as porções norte e sul do granito com valores mais elevados deste radioelemento. Valores intermediários e baixos restringem-se aos quartzitos, pegmatitos e coberturas arenosas por toda extensão norte, centro e sudoeste. A forma e a localização das anomalias de tório distinguem-se das do urânio e do potássio. Há uma anomalia alongada e maior no norte da área e outra no sul não caracterizadas para estes radioelementos. A concentração de tório nesses locais pode ainda estar realçada por concentração de minerais resistatos nas coberturas residuais. A imagem da contagem 

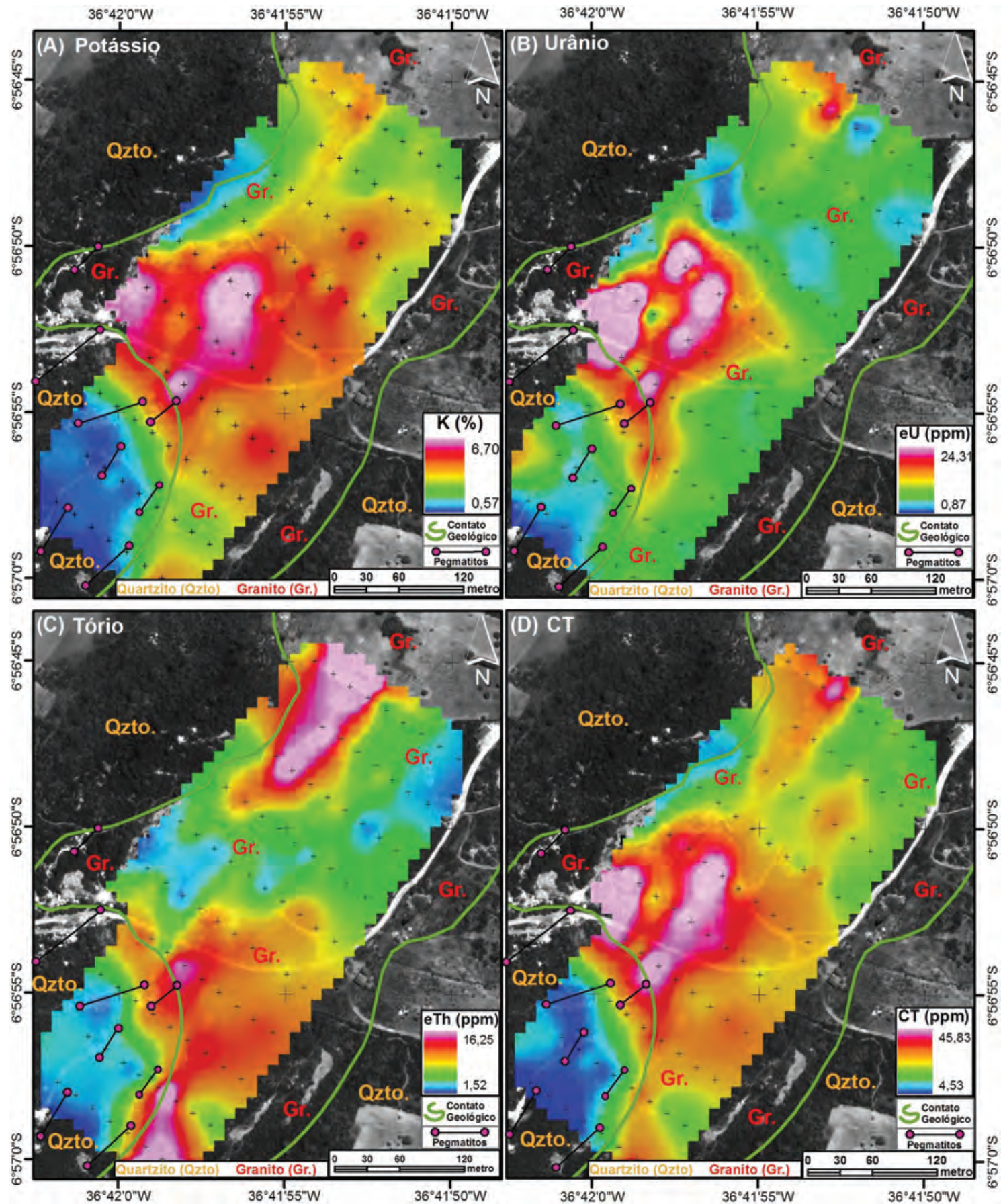

Figura 6 - (A) imagem do potássio; (B) do urânio; (C) do tório; e (D) da contagem total (CT) do granito Galo Branco, sobrepostas à imagem pancromática do sensor orbital QuickBird, de alta resolução espacial $(0,65 \mathrm{~cm})$.

total mapeia o contato granito-quartzitos inferido em campo no setor sul (Fig. 6C), além de pequena exposição, na porção norte. A contagem total tem o mesmo comportamento do potássio no mapeamento do contato destas rochas a NW.
As imagens dos canais individuais mostram que os radioelementos não se superpõem, evidenciando comportamento e distribuição espacial distintos. Enquanto o potássio e 0 urânio se concentram na parte central do corpo, o tório está mais 


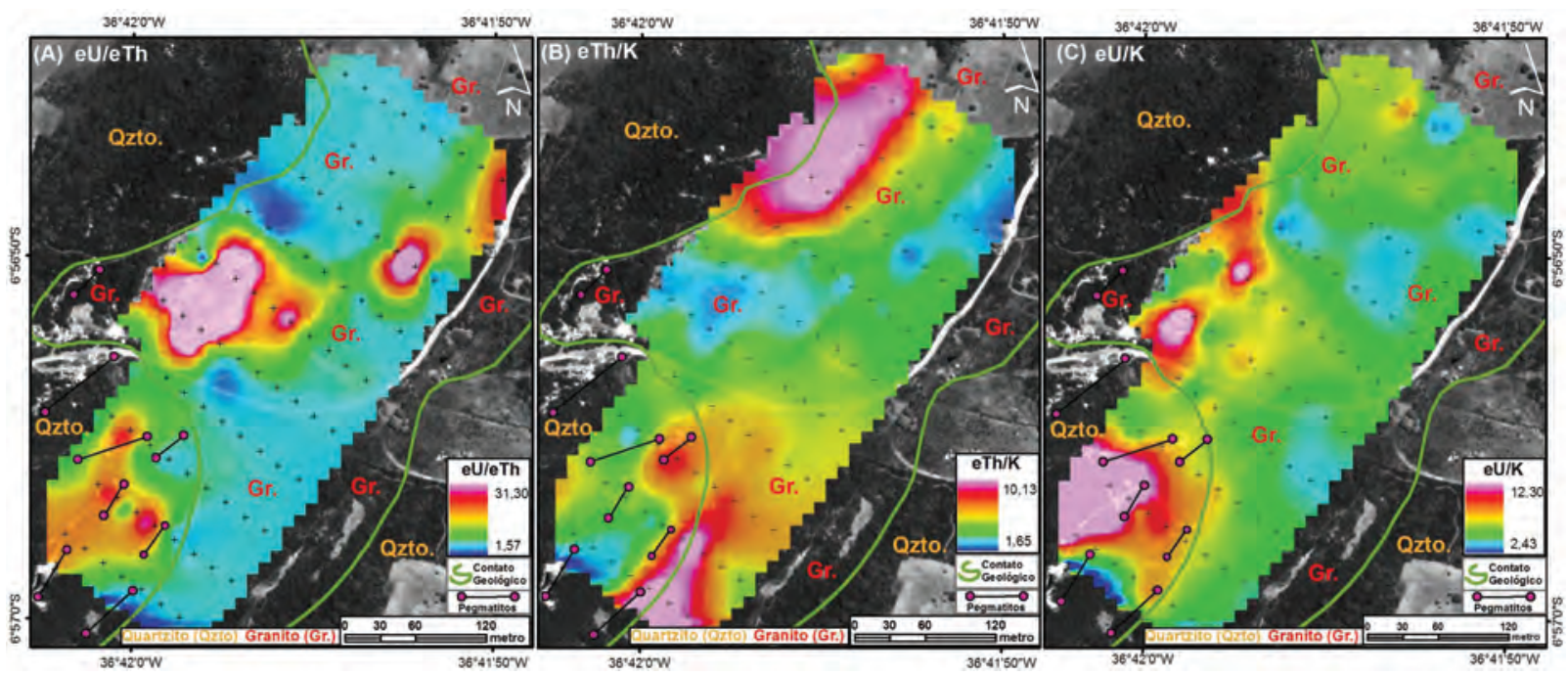

Figura 7 - (A) razão eU/eTh; (B) razão eTh/K; (C) razão eU/K.

presente nas bordas norte e sul, indicando heterogeneidades modais e mineralógicas decorrentes de processos de diferenciação e cristalização da rocha, e/ou ligada a hidrotermalismo que podem controlar as suas distribuições de minerais secundários. A ação do ciclo exógeno pode ainda ter promovido a concentração de minerais de tório nas coberturas superficiais.

A Figura 7 apresenta a imagem da razão eU/eTh. A maior parte da área é caracterizada por baixos valores desta razão, principalmente nos setores norte e sul. São observadas anomalias isoladas na porção nordeste, sendo que uma delas se encontra próxima ao corpo central e três delas ao sul, sobre diques de pegmatitos encaixados em quartzitos (Fig. $7 \mathrm{~A}$ ). 0 realce obtido pela razão eU/eTh revela que o urânio, ao contrário do tório, pode ter permanecido nos estágios finais de cristalização desses pegmatitos. Esta interpretação independe do fato de haver material lavado nas cavas e abandonados em superfície, dado que este material foi retirado do dique em subsuperfície.

A imagem da razão eTh/K mostra anomalias nos setores norte e sul do granito. Há um certo espalhamento da anomalia para NW, na direção dos quartzitos, que pode estar associada à permanência de minerais resistatos e pesados nas cascalheiras e areias grossas residuais. Também na direção norte ocorrem afloramentos do granito. Esta razão também mapeia 0 contato do granito com os quartzitos ao sul.

A Figura 7C apresenta a razão eU/K. Nela se destacam duas pequenas áreas com valores elevados de urânio localizadas no centro do corpo principal e outra maior concentrada nos quartzitos do segmento sul. Parte dessa anomalia se deve à ocorrência de diques de pegmatitos no local (razão eU/eTh - Fig. 7A).
Outra parte se deve ao material possivelmente removido deste local e espalhado pelos caminhos e ao lado das escavações. Medida gamaespectrométrica terrestre nos quartzitos revelou valores de 0,2\% de K, 0,6 ppm de eU e 0,1 ppm de eTh. São valores muito baixos, apesar do urânio apresentar teor mais elevado dos três radioelementos. A existência de material de rejeito de caulim em superfície dificulta a separação entre 0 material autóctone e alóctone no terreno.

\section{CONCLUSÕES}

As conclusões deste estudo podem ser assim resumidas: (i) os dados aerogamaespectrométricos mostraram nítida diferença das assinaturas referentes às litologias das regiões norte e sul da área de estudo; ii) os valores anômalos de potássio possibilitaram caracterizar os conjuntos litológicos referentes aos quartzitos, metaconglomerados, paragnaisses e granitos, enquanto os valores mais baixos se relacionam aos biotita xistos da Formação Seridó e às coberturas colúvio-eluviais; ii) foi possível discriminar os quartzitos das regiões norte e sul, com base na assinatura gamaespectrométrica destacada do tório (eTh) e da razão eTh/K nestes últimos; (iii) as razões eU/eTh e eU/K diferenciam um conjunto de granitos, dispostos segundo um trend na porção leste da Serra das Queimadas, o qual se estende desde Ponta da Serra, ao norte, até Boqueirãozinho, ao sul; (iv) a comparação entre os dados geofísicos e geológicos permite concluir que os granitos, assim como alguns dos pegmatitos presentes na região situada no entorno do granito Galo Branco, exibem evidências de enriquecimento em urânio, possivelmente decorrente de processos relacionados aos estágios tardios de evolução e cristalização 
destas rochas; (v) foram identificadas evidências de processos de alteração hidrotermal, com illita/sericita de alto grau de ordenamento estrutural; (vi) no entorno dos granitos foram encontrados somente pegmatitos homogêneos, caulinizados, o que dificulta estabelecer nessa área qualquer relação com pegmatitos heterogêneos mineralizados; viii) demonstrou-se que os dados do Projeto Aerogeofísico Seridó, apesar de sua baixa resolução espacial, podem ser úteis na caracterização, diferenciação e mapeamento de granitos pegmatíticos e pegmatitos na PPB, através dos métodos e técnicas de processamento aqui empregados; ix) o mapeamento geológico de detalhe desses e de outros granitos da região poderá esclarecer as relações entre eles e os pegmatitos heterogêneos mineralizados, além de verificar a existência ou não de vários campos de granitos e pegmatitos associados, conforme sugerido por Beurlen et al. (2008).

\section{AGRADECIMENTOS}

Os autores agradecem à FAPESP pela concessão de auxílio financeiro ao projeto de pesquisa (Processo FAPESP 2005/05138-4), bem como à CPRM - Serviço Geológico do Brasil pela cessão dos dados aerogeofísicos digitais do Projeto Seridó. 0 primeiro autor agradece à Universidade Federal do Rio Grande do Norte (UFRN) pelo apoio para realização de pós-graduação. Também são devidos agradecimentos ao Instituto de Geociências da Universidade Estadual de Campinas (Unicamp) pela disponibilização de material e laboratórios. A.M. Silva, A.P. Crósta, F.J.F. Ferreira e H. Beurlen agradecem ao CNPq pelas respectivas bolsas de Produtividade em Pesquisa. Aos colaboradores e revisores pelas sugestões, as quais aperfeiçoaram o texto final.

\section{REFERÊNCIAS}

ALMEIDA FFM de, HASUI Y, BRITO NEVES BB \& FUCK RA. 1977. Províncias Estruturais Brasileiras. In: Simpósio de Geologia do Nordeste, 8: 1977, Campina Grande. Atas... Campina Grande: SBG, 1977. p. $363-391$.

ALMEIDA FFM de, HASUI Y, BRITO NEVES BB \& FUCK RA. 1981. Brazilian Structural provinces: An introduction. Earth Science Review, 17: $1-29$.

ANGELIM LAA, VASCONCELOS AM, GOMES JRC, WANDERLEY AA, FORGIARINI LL \& MEDEIROS M de F. 2004. Folha SB-24-Jaguaribe. In: SCHOBBENHAUS C, GONÇALVES JH, SANTOS JOS, ABRAM MB, LEÃO NETO R, MATOS GMM, VIDOTTI RM \& RAMOS MAB (Eds.). Carta Geológica do Brasil ao Milionésimo, SIG. Programa Geologia do Brasil. CPRM, Brasília. CD-ROM.

ARCHANJO CJ \& SALIM J. 1986. Posição estratigráfica da Formação Seridó no contexto estratigráfico regional (RN-PB). In: Simpósio de Geo- logia do Nordeste, 1986, João Pessoa. Anais... João Pessoa - PB, 12: 270-281.

BARMP - Brazil Airborne Radiometric Mapping Project. 1997. Technical report and survey atlas. A collaboration between Paterson, Grant \& Watson Limited (PGW), Companhia de Pesquisa de Recursos Minerais (CPRM) and Geological Survey of Canada (GSC), Rio de Janeiro, RJ, 30 p. (inédito)

BAUMGARTNER R, ROMER RL, MORITZ R, SALLET R \& CHIARADIA M. 2006. Columbite-tantalite-bearing granitic pegmatites from the Seridó Belt, northeastern Brazil: genetic constraints from U-Pb dating and $\mathrm{Pb}$ isotopes. The Canadian Mineralogist, 44: 69-86.

BECEGATO VA \& FERREIRA FJF. 2005. Gamaespectrometria, resistividade elétrica e susceptibilidade magnética de solos agrícolas no noroeste do Estado do Paraná. Revista Brasileira de Geofísica, 23(4): 371-405.

BEURLEN H, DA SILVA MRR, THOMAS R, SOARES DR \& OLIVIER P. 2008. Nb-Ta-(Ti-Sn)-0xide mineral chemistry as tracers of rare-element granitic pegmatite fractionation in the Borborema Province, Northeastern Brazil. Mineralium Deposita, 43(2): 207-228.

BEURLEN H, RHEDE D, DA SILVA MRR, THOMAS R \& GUIMARÃES IP. 2009. Petrography, Geochemistry and Chemical Electron Microprobe U-Pb-Th dating of Pegmatitic Granites in Borborema Province, NorthEastern Brazil: a Possible Source of Rare Element Granitic Pegmatites. Terrae, 6(1-2): 59-71.

BLUM MLB. 1999. Processamento e interpretação de dados de geofísica aérea no Brasil Central e sua aplicação à geologia regional e à prospecção mineral. Tese (Doutorado em Geociências), Instituto de Geociências, Universidade de Brasília, Brasília, 229 p.

BOYLE RW. 1982. Geochemical prospecting for uranium and thorium deposits. Amsterdam, Elsevier. 498 p.

BRIGGS IC. 1974. Machine contouring using minimum curvature. Geophysics, 30(1): 39-48.

BRITO NEVES BB, SANTOS EJ \& VAN SCHMUS WR. 2000. Tectonic history of the Borborema Province, northeastern Brazil. In: CORDANI UG, MILANI EJ, THOMAZ FILHO A \& CAMPOS DA (Eds.). Tectonic Evolution of South America. International Geological Congress, 31. p. 151-182.

CPRM - Serviço Geológico do Brasil. 1994. Catálogo geral de produtos e serviços. Geologia. Levantamentos Aerogeofísicos. Base de dados AERO. $2^{\mathrm{a}}$ ed. Rio de Janeiro: Diretoria de Geologia e Recursos Hídricos, $367 \mathrm{p}$.

CPRM - Serviço Geológico do Brasil. 2008. Base de Metadados Aerogeofísicos. Catálogo de Projetos Aerogeofísicos. Rio de Janeiro: Divisão de Geofísica - DIGEOF. Disponível em:

$<$ http://www.cprm.gov.br/aero/1000/aero1000.htm>. Acesso em: 5 mar. 2008. 
DA SILVA MRR. 1993. Petrographical and geochemical investigations of pegmatites in the Borborema Pegmatitic Province of Northeastern Brazil. Tese de Doutorado. Ludwig-Maximilians-Universität, München, $305 \mathrm{p}$.

DA SILVA MRR \& GUIMARÃES IP. 1992. Caracterização geoquímica da granitogênese brasiliana na Província Pegmatítica da Borborema. In: XXXVII Congresso Brasileiro de Geologia. São Paulo, p. 38-40.

DA SILVA MRR \& STAERK H. 1989. Granitos pegmatíticos férteis na Província Pegmatítica da Borborema. In: Simpósio de Geologia do Nordeste. Atas. Fortaleza. Boletim 11, 13: 134-136.

DA SILVA MRR, HÖLL R \& BEURLEN H. 1995. Borborema Pegmatitic Province: geological and geochemical characteristics. Journal of South American Earth Science, 8: 355-364.

DANTAS EL, SILVA AM, ALMEIDA T \& MORAES RAV de. 2003. Old geophysical data applied to modern geological mapping problems: a casestudy in the Seridó Belt, NE Brazil. Revista Brasileira de Geociências, 33(2-Suplemento): 65-72.

DICKSON BL \& SCOTT KM. 1997. Interpretation of aerial gamma-ray surveys-adding the geochemical factors. AGSO Journal of Australian Geology \& Geophysics, 17(2): 187-200.

EBERT H. 1970. The Precambrian geology of the "Borborema"-Belt (States of Paraíba and Rio Grande do Norte; northeastern Brazil) and origin of its mineral provinces. International Journal of Earth Sciences, 59: 1292-1326.

FERREIRA CA. 1997. Programa Levantamentos geológicos básicos do Brasil. Caicó, Folha SB.24-Z-B. Estados da Paraíba e Rio Grande do Norte. Escala 1:250.000. Geologia e Metalogênese. Brasília. CPRM. 152 p. il 2 mapas.

FERREIRA JAM \& ALBUQUERQUE JPT. 1969. Sinopse da geologia da Folha Seridó. SUDENE, Divisão de Geologia, Série Geologia Regional. 18: $52 \mathrm{p}$.

FERREIRA CA \& SANTOS EJ. 2000. Programa Levantamentos Geológicos Básicos do Brasil. Jaguaribe SE. Folha SC. 24-Z. Estados do Ceará, Rio Grande do Norte, Paraíba e Pernambuco. Escala 1:500.000. Geologia e metalogênese. Recife: CPRM, 2000. CD-ROM.

FERREIRA FJF, FRUCHTING A, GUIMARÃES GB, ALVES LS, MARTIN VMOM \& ULBRICHT HHGJ. 2009. Levantamentos Gamaespectrométricos em Granitos Diferenciados. II: 0 Exemplo do Granito Joaquim Murtinho, Complexo Granítico Cunhaporanga, Paraná. Geologia USP, Série Científica, São Paulo, 9(1): 55-72.

GALBRAITH JH \& SAUNDERS DF. 1983. Rock classification by characteristics of aerial gamma-ray measurements. Journal of Geochemical Exploration, 18: 49-73.

HAUFF P, KRUSE F, MADRID R, FRASER S, HUNTINGTON J, JONES M \& WATTERS S. 1991. Illite crystallinity - case histories using X-ray dif- fraction and reflectance spectroscopy to define ore host environments. In: Eight Thematic Conference on Geologic Remote Sensing, 1: 447-458.

HEIER KS \& RHODES JM. 1966. Thorium, Uranium and Potassium concentrations in granites and gneiss of the Rum Jungle Complex, Northern Territory, Australia. Economic Geology. 61: 563-571.

IAEA - International Atomic Energy Agency. 2003. Guidelines for radioelement mapping using gamma ray spectrometry data. IAEA-TECDOC1363. IAEA, Vienna, $173 p$.

IPEN - Instituto de Pesquisas Energéticas e Nucleares. 2006. Espectrometria gama: Procedimento. São Paulo: IPEN, (PO-LRA-0901-03).

JARDIM DE SÁ EF. 1984. Geologia da região do Seridó: reavaliação de dados. In: Simpósio de Geologia do Nordeste, 11: Natal. Atas... Natal: SBG, p. 278-296.

JARDIM DE SÁ EF. 1994. A Faixa Seridó (Província Borborema NE do Brasil) e o seu significado geodinâmico na Cadeia Brasiliano/PanAfricana. Brasília, Tese (Doutorado em Geociências), Instituto de Geociências, Universidade de Brasília. 803 p.

JARDIM DE SÁ EF \& SALIM J. 1980. Reavaliação dos conceitos estratigráficos na região do Seridó (RN-PB). Mineração e Metalurgia, Rio de Janeiro, 417: 16-28.

JARDIM DE SÁ EF, LEGRAND JM \& McREATH I. 1981. "Estratigrafia" de rochas granitóides na região do Seridó (RN-PB) com base em critérios estruturais. Revista Brasileira de Geociências, 11(1): 50-57.

JARDIM DE SÁ EF, LEGRAND JM, GALINDO AC \& HACKSPACHER PC. 1986. Granitogênese Brasiliana no Seridó: 0 Maciço de Acari (RN). Revista Brasileira de Geociências, 16: 95-105

JOHNSTON JR WD. 1945. Os pegmatitos berilo-tantalíferos da Paraíba e Rio Grande do Norte, no Nordeste do Brasil. Rio de Janeiro, DNPMDFPM, 85 p. (Boletim 72).

KILEEN PG. 1979. Gamma-ray spectrometric methods in uranium exploration - application and interpretation. In: HOOD PJ (Ed.). Geophysics and Geochemistry in the Search for Metallic Ores. Geological Survey of Canada, Economic Geology Report, 31: 163-229.

LASA. 1974. Levantamento aerogeofísico - Magnetometria e Cintilometria com discriminação de energia. Projeto Seridó, Relatório Final. CPRM/DNPM/CNEN. Recife. n. Paginado (inédito).

LEGRAND JM, MELO JR G, ARCHANJO CJ, SALIM J, SOUZA LC de \& MAIA HN. 1993. Mineralizações da Faixa Seridó: um processo hidrotermal do fenômeno tectono-magmático brasiliano. In: Simpósio de Geologia do Nordeste. Atas. Natal., 15: 185-187.

LUIZ-SILVA W. 2000. Mineralizações auríferas em veios de quartzo na Faixa Seridó, NE do Brasil: Exemplo de depósitos de ouro de fáceis anfibolito em faixa móvel proterozóica. Tese de Doutorado. UNESP. Rio Claro, 2v. 153 p. 
MAURICE YT \& CHARBONNEAU BW. 1987. U and Th concentration processes in Canadian granitoids, their detection by airborne gamma ray spectrometry and their relationship to granophile mineralization. Revista Brasileira de Geociências, 17(4): 644-646.

MINTY BRS. 1997. Fundamentals of airborne gamma-ray spectrometry AGSO Journal of Australian Geology \& Geophysics, 17(2): 39-50.

OLIVEIRA RG. 2008. Arcabouço geofísico, isostasia e causas do magmatismo Cenozóico da Província Borborema e de sua margem continental (Nordeste do Brasil). Tese (Doutoramento em Geofísica e Geodinâmica) Universidade Federal do Rio Grande do Norte. Natal, RN Brasil. 411 p.

OLIVEIRA RG, SANTOS EJ, DA SILVA JR JM \& LINS CAC. 2001. Magnetic, gravity and gamma-ray spectrometry responses of tectonostratigraphic terranes in the Jaguaribe-SE sheet (SB24Z), Northeastern Brazil. In: International Congress of Brazilian Geophysical Society, 2001. Salvador. Integration Studies: Case Histories, 2001. p. 497-500. CD-ROM.

PASCHOLATI EM, DA SILVA CL, COSTA SS, OSAKO LS, AMARAL G \& RODRIGUEZ IP. 2003. Novas ocorrências de urânio na região de Lagoa Real, a partir da superposição de dados geofísicos, geológicos e de sensoriamento remoto. Revista Brasileira de Geociências, 33(2Suplemento): 91-98.

PIRES ACB. 1995. Identificação geofísica de áreas de alteração hidrotermal, Crixás-Guarinos, Goiás. Revista Brasileira de Geociências, 25(1): 61-68.

PONTUAL S, MERRY N \& GAMSON P. 1997. Spectral interpretation field manual, G-MEX. Ed. AusSpec International Pty. Ltd. vol. 1, 169 p.

PORTNOV AM. 1987. Specialization of rocks toward potassium and thorium in relation to mineralization. International Geological Review, 29: $326-344$.

SANTOS EJ \& BRITO NEVES BB. 1984. Província Borborema In: ALMEIDA FFM \& HASUI Y. O Pré-cambriano do Brasil. São Paulo: Edgard Blucher, 123-187.

SANTOS EJ, VAN SCHMUS WR, BRITO NEVES BB, OLIVEIRA RG \& MEDEIROS V. 1999. Terranes and their boundaries in the Proterozoic Borborema Province, NE Brazil. In: SBG, Simpósio Nacional de Estudos Tectônicos, 7, Lençóis, Bahia. Anais... Lençóis/BA, SBG. 1999. p. 121-124.

SAUNDERS DF, BURSON KR, BRANCH JF \& THOMPSON CK. 1993.
Relation of thorium-normalized surface and aerial radiometric data to subsurface petroleum accumulations. Geophysics, 58(10): 1417-1427.

SCORZA EP. 1944. Província Pegmatítica da Borborema (Nordeste do Brasil). MA, DNPM, DGM. RJ. 58 p. (Boletim 112).

SHIVES RBK, CHARBONNEAU BW \& FORD KL. 2000. The detection of potassic alteration by gamma-ray spectrometry - Recognition of alteration related to mineralization. Geophysics, 65(6): 2001-2011.

SILVA SMP da. 2009. Espectroscopia de imageamento e gamaespectrometria aérea e terrestre de pegmatitos e granitos da porção sul da Província Pegmatítica da Borborema (PPB), Nordeste do Brasil. Tese de Doutorado, Universidade Estadual de Campinas. Campinas, São Paulo, 2009. $173 \mathrm{p}$.

SILVA SMP da, CRÓSTA AP, FERREIRA FJF, BEURLEN H, SILVA AM \& DA SILVA MRR. 2010. Identificação gamaespectrométrica de placeres rutilo-monazíticos neoproterozóicos no sul da Faixa Seridó, nordeste do Brasil. Revista Brasileira de Geofísica, 28(1): 61-77.

SRODON J \& EBERL DD. 1984. Illite. In: Micas. Reviews in Mineralogy. Ed. Bailey. S.W. vol. 13. Mineralogical Society of America. p. 495-539.

ULBRICHT HHGJ, ULBRICHT MNC, FERREIRA FJF, ALVES LS, GUIMARÃES GB \& FRUCHTING A. 2009. Levantamentos Gamaespectrométricos em Granitos Diferenciados. I: Revisão da Metodologia e do Comportamento Geoquímico dos Elementos K, Th e U. Geologia USP, Série Científica, São Paulo, 9(1): 33-53.

VAN SCHMUS WR, BRITO NEVES BB, WILLIAMS IS, HACKSPACHER $P C$, FETTER AH, DANTAS EL \& BABINSKI M. 2003. The Seridó Group of NE Brazil, a late Neoproterozoic pre- to syn-collisional basin in west Gondwana: insights from SHRIMP U-Pb detrital zircon ages and Sm-Nd crustal residence (TDM) ages. Precambrian Research, 127(4): 287-327.

WEBB PC, THOMPSON M, POTTS PJ, WATSON JS \& KRIETE C. 2008. GeoPT23 - An international proficiency test for analytical geochemistry laboratories - report on round 23. (Separation Lake pegmatite, OU-9) and 23A (manganese nodule, FeMn-1) / September 2008. GeoPT23/23A Report.

ZHANG G, WASYLIUK K \& PAN Y. 2001. The characterization and quantitative analysis of clay minerals in the Athabasca Basin, Saskatchewan: application of short wave infrared reflectance spectroscopy. The Canadian Mineralogist, 39: 1347-1363. 


\section{NOTAS SOBRE OS AUTORES}

Sebastião Milton Pinheiro da Silva. Geólogo pela UFPE em 1976 e Mestre em Sensoriamento Remoto e Aplicações pelo INPE em 1991. Atuou na Companhia de Pesquisa de Recursos Minerais - CPRM de 1976 a 1999. Atualmente é Professor Adjunto do Departamento de Geografia da UFRN onde leciona disciplinas de geologia e geotecnologias. Atua nas áreas de Sensoriamento Remoto, Geoprocessamento e Gamaespectrometria aplicadas à exploração e pesquisa mineral, ao meio ambiente e no ensino.

Alvaro Penteado Crósta. Graduou-se em Geologia pela USP (1977), concluiu o mestrado no Instituto de Pesquisas Espaciais - INPE (1982) e 0 doutorado no Imperial College of Science \& Technology, University of London (1990). Realizou pós-doutorado junto ao Desert Research Institute, University of Nevada, Reno, entre 1995-1996. É Professor Titular do Instituto de Geociências da Universidade Estadual de Campinas, e Bolsista de Produtividade em Pesquisa do Conselho Nacional de Desenvolvimento Científico e Tecnológico/DF. Atua na área de Sensoriamento Remoto e Exploração Mineral e de Geologia Planetária/Crateras de Impacto Meteorítico.

Francisco José Fonseca Ferreira. Geólogo (UFPE-1970), Especialista em Geofísica Aplicada (UFBA-1974), Mestre e Doutor em Ciências (USP-1982; USP1991), Bolsista de Produtividade em Pesquisa do CNPq, com atuação profissional na CPRM (1972-1980) e no IPT (1980-1990). Atualmente é Professor Associado do Departamento de Geologia da UFPR, onde ministra disciplinas de geofísica aplicada nos cursos de graduação e pós-graduação. A partir de 1998 coordena o Laboratório de Pesquisas em Geofísica Aplicada - LPGA/UFPR, onde desenvolve pesquisas multidisciplinares aplicadas ao ambiente, à exploração mineral e de águas subterrâneas.

Hartmut Beurlen. Geólogo (UFPE-1965), doutorado no Mineralogisch Petrographisches Institut, Universität Heidelberg (Ruprecht-Karls) (1973), e pós-doutorado no Dept. of Earth and Space Sciences, University of California (1989). Trabalhou na SUDENE (1965-1975). É Professor do Curso de Pós-Graduação em Geociências da UFPE e Bolsista de Produtividade em Pesquisa do CNPq. É membro do corpo editorial da Revista Brasileira de Geociências e Estudos Geológicos. Trabalha com metalogenia e petrologia, com ênfase em petrografia de minerais opacos, estudo de inclusões fluidas e geoquímica, concentrando as pesquisas mais recentes na Província Pegmatítica da Borborema, Nordeste do Brasil.

Adalene Moreira Silva. Engenheira Geóloga (1989) graduada pela Universidade Federal de Ouro Preto, Mestre (1992) e Doutora em Geologia (1999) pela Universidade de Brasília. Atuou como pesquisadora do Serviço Geológico Americano (1997-1999), Professora Visitante da Universidade de Brasília (2000-2002), Pesquisadora (05/2002-04/2003) e Professora do Instituto de Geociências da Unicamp. (04/2003-10/2005). É Professora e Coordenadora de Extensão do Instituto de Geociências da Universidade de Brasília e Professora Colaboradora do Instituto de Geociências da Unicamp. Desenvolve projetos sobre novas técnicas de processamento, interpretação e integração de dados aplicados à exploração mineral, hidrogeologia e ambiente. É Bolsista de Produtividade em Pesquisa do CNPq.

Luiz Fernando dos Santos. Bacharel em Geologia (Jul/2008) pela Universidade Estadual de Campinas - UNICAMP. Atua na área de geotecnologias aplicadas à geologia: Sistemas de Informações Geográficas, sensoriamento remoto, geofísica e cartografia geológica. 